This is an author produced version of a paper published in Acta Neurochirurgica. Supplement. This paper has been peer-reviewed but does not include the final publisher proof-corrections or journal pagination.

Citation for the published paper:

Nordstrom, C H

“The Lund concept: is this logical?”

Acta Neurochir Suppl. 2005;95:475-80.

Access to the published version may require journal subscription.

Published with permission from: Springer. 


\title{
The Lund concept: Is this logical?
}

\author{
Carl-Henrik Nordström
}

Department of Neurosurgery, Lund University Hospital, Lund, Sweden

Address:

Carl-Henrik Nordström

Department of Neurosurgery

University Hospital

S-221 85 Lund

Sweden

Telephone: 46-46-171272

Fax: 46-46-189287

e-mail: carl-henrik.nordstrom@neurokir.lu.se 


\section{Summary}

The optimal therapy of sustained increase in intracranial pressure (ICP) is still controversial. The "Lund concept" is based on the physiological volume regulation of the intracranial compartments. In addition to its other functions the blood-brain barrier (BBB) is the most important regulator of brain volume. Water exchange across the intact BBB is counteracted by the low permeability to crystalloids (mainly $\mathrm{Na}^{+}$and $\left.\mathrm{Cl}^{-}\right)$combined with the high osmotic pressure $(5,700 \mathrm{~mm} \mathrm{Hg})$ on both sides of the BBB. If the BBB is disrupted transcapillary water transport will be determined by the differences in hydrostatic and colloid osmotic pressure between the intra- and extracapillary compartments. Under pathological conditions pressure autoregulation of cerebral blood flow is often impaired and intracapillary hydrostatic pressure will depend on variations in systemic blood pressure.

The "Lund concept" can be summarized in four paragraphs: I. Reduction of stress response and cerebral energy metabolism; II. Reduction of capillary hydrostatic pressure; III. Maintenance of colloid osmotic pressure and control of fluid balance; IV. Reduction of cerebral blood volume. The efficacy of the treatment protocol has been evaluated in experimental and clinical studies regarding the physiological and biochemical (utilizing intracerebral microdialysis) effects. The clinical experiences have been favourable.

Key-words: Brain oedema, blood-brain barrier, microdialysis

Except for decompressive craniectomy all treatments of increased intracranial pressure (ICP) are directed towards decreasing the volume of one or more of the intracranial components:

$$
\mathrm{V}_{\text {intracran }}=\mathrm{V}_{\text {blood }}+\mathrm{V}_{\text {brain }}+\mathrm{V}_{\mathrm{CSF}}+\mathrm{V}_{\text {mass lesion }} \quad \text { (Eq. 1) }
$$

Surgical treatments include evacuation of mass lesions $\left(\mathrm{V}_{\text {mass lesion }}\right)$ and, in some cases, drainage of $\mathrm{CSF}\left(\mathrm{V}_{\mathrm{CSF}}\right)$. The importance of early and adequate surgical evacuation of focal mass lesions is well documented and will not be discussed further in this presentation. The regulation of the remaining two volumes $\left(\mathrm{V}_{\text {blood }}\right.$ and $\left.\mathrm{V}_{\text {brain }}\right)$ is in focus for the (non-surgical) intensive care. However, the surgical and non-surgical treatments are closely connected since all surgical therapies have one consequence in common: they all reduce tissue interstitial pressure. As discussed below, in a situation with increased permeability of the blood-brain barrier (BBB), a decrease in tissue pressure will lead to increased transcapillary water filtration. The consequences are well known to all neurosurgeons: the gradual 
increase in ICP almost always observed after evacuation of focal lesions; the collapse of the ventricles often induced by ventricular drainage; the bulging of cerebral tissue through the bone defect after craniectomy. The rapid change in volume obtained by surgical treatment should accordingly always be combined with a non-surgical therapy aiming primarily at a slow and lasting reduction in brain water content.

\section{Blood-brain barrier permeability}

Like other organs the volume regulation of the brain is primarily determined by mechanisms controlling the water exchange across the capillaries. Regarding these mechanisms the brain differs from other organs in its highly sophisticated capillary membrane function - the BBB. In addition to its other physiological functions the $\mathrm{BBB}$ is the most important regulator of cerebral volume (8).

The flux of water across a membrane or microvascular bed $\left(\mathrm{J}_{\mathrm{v}}\right)$ is described by the equation

$$
\mathrm{J}_{\mathrm{V}}=\mathrm{L}_{\mathrm{p}} \times \mathrm{A} \times\left[\Delta \mathrm{P}-\sum \sigma_{\mathrm{s}} \times \Delta \Pi_{\mathrm{s}}\right] \quad(\text { Eq. } 2)
$$

where $\mathrm{L}_{\mathrm{p}}$ is hydraulic conductivity, $\mathrm{A}$ is the surface area available for fluid exchange, $\Delta \mathrm{P}$ is the transcapillary hydrostatic pressure difference, $\Delta \Pi_{\mathrm{s}}$ the transcapillary osmotic pressure difference and $\sigma_{\mathrm{S}}$ the reflection coefficient of each solute (s) of the system. The transcapillary water transport is accordingly defined by the difference in hydrostatic pressure $(\Delta \mathrm{P})$, the osmotic pressure gradient $\left(\Delta \Pi_{\mathrm{s}}\right)$, the endothelial component which will determine which solutes are reflected and will contribute to the osmotic pressure gradient $\left(\sigma_{\mathrm{s}}\right)$, and the hydraulic conductance of the capillary wall $\left(\mathrm{L}_{\mathrm{p}} \mathrm{x} A\right)$. The two major solutes of biological fluids $\left(\mathrm{Na}^{+}\right.$and $\left.\mathrm{Cl}^{-}\right)$have a blood-brain barrier reflection coefficient of 1.0. Water passing the BBB in any direction will thus be virtually devoid of crystalloids and an opposing osmotic gradient, which counteracts further fluid transport, will immediately be created.

According to eq. 2 the magnitude of the hydraulic conductance $\left(\mathrm{L}_{\mathrm{p}} \times \mathrm{A}\right)$ describes the rate by which the fluid is transferred across the capillary membrane whenever there is a driving force $(\Delta \mathrm{P}-\Sigma \sigma \times \Delta \Pi)$. Accordingly, the only way of inducing transcapillary filtration or absorption is to disturb the balance between the hydrostatic and osmotic forces across the capillary membrane. For two reasons the magnitude of the cerebral perfusion pressure (CPP) is of less importance for brain volume under normal conditions. Firstly, intracapillary pressure and cerebral blood flow are physiologically tightly autoregulated and variations in systemic blood pressure are generally not transmitted to cerebral 
capillaries. Secondly, transcapillary fluid exchange is effectively counteracted by the low permeability to crystalloids combined with the high osmotic pressure of 5,700 $\mathrm{mm} \mathrm{Hg}$ on both sides of the BBB (8). This contrasts to most other capillary regions where the osmotic pressure force is mainly derived from the difference between plasma and interstitial colloid osmotic pressure approximately balancing the transcapillary hydrostatic pressure $(20-25 \mathrm{mmHg})$. Under pathophysiological conditions the regulation of brain volume may be completely altered. In these conditions pressure autoregulation is often impaired and the BBB may have an increased permeability for crystalloids or even for large molecules. The regulation of brain volume will then depend on the balance between the transcapillary hydrostatic pressure and the transcapillary colloidal osmotic pressure.

\section{Cerebral blood flow and cerebral blood volume}

The tight regulation of cerebral blood flow (CBF) primarily secures a continuous and sufficient supply of glucose and oxygen to cover the high cerebral metabolism. Two secondary effects of CBF regulation have important consequences for the regulation of ICP: the intracapillary hydrostatic pressure and the intracerebral blood volume (mainly within the venous compartment). Several important principles within intracranial dynamics can be described in relation to the conventional physiological regulatory mechanisms of the cerebral blood flow: pressure autoregulation, $\mathrm{CO}_{2}$-regulation, and metabolic regulation.

Pressure autoregulation implies that blood flow remains relatively constant despite variations in CPP within defined limits. The phenomenon is present in many organs and appears to be most prominent in the brain and in the kidneys. In physiological literature autoregulation is usually described as a mechanism, which serves the purpose of keeping intracapillary hydrostatic pressure constant (c.f. above).

A rapid reduction of intracranial blood volume is conventionally obtained by controlled hyperventilation via the $\mathrm{CO}_{2}$-regulation of $\mathrm{CBF}$. The effect is attained by a $\mathrm{pH}$ dependent constriction of precapillary resistance vessels. Prolonged hyperventilation is probably of limited value or may even be harmful since pronounced hyperventilation carries the risk of inducing focal ischemia. Further, the reduction of $\mathrm{CBF}$ and $\mathrm{CBV}$ during hyperventilation is transient in spite of preserved hypocapnia. Finally, due to impaired cerebrovascular $\mathrm{CO}_{2}$-reactivity hyperventilation is often not effective in reducing $\mathrm{CBV}$ in the most severely brain injured patients $(10,21)$. 
A lasting vasoconstriction and reduction of CBV can be achieved through reduction of cerebral energy metabolism e.g. by barbiturates (15). This mechanism appears to be effective only in patients with preserved cerebrovascular $\mathrm{CO}_{2}$-reactivity (15). In addition, prolonged high-dose barbiturate treatment is associated with pulmonary, cardiovascular and other serious complications (22).

Since in the brain, like in other organs, about $70 \%$ of blood volume is located within the venous compartment it might be possible to induce a lasting reduction of $\mathrm{CBV}$ with a minimal effect on $\mathrm{CBF}$ by inducing a pharmacological constriction of the capacitance vessels. Dihydroergotamine (DHE) is known to primarily constrict venous capacitance vessels within the peripheral circulation and has also been shown to decrease ICP in patients with severe head injuries (9). This effect is obtained although CBF remains unaffected or increases $(4,13)$. DHE has been shown to decrease ICP also in patients with impaired $\mathrm{CO}_{2}$-reactivity (4) and in vitro studies have shown that DHE has a more pronounced constrictor effect on isolated human cortical veins than arteries (14).

\section{Pathophysiological aspects of disturbed brain volume regulation}

No techniques are available for quantitative measurements of cerebral intracapillary hydrostatic pressure or the effects of increased hydrostatic pressure on water transport across the BBB. Some aspects may however be studied in a model system utilizing a denervated cat skeletal muscle enclosed in a plethysmograph $(1,9)$. This model simulates the pathophysiological situation in a damaged brain since muscle capillaries are permeable for water and most solutes but much less permeable for proteins $(\sigma \approx$ 0.8-0.9). Further, pressure autoregulation of blood flow is impaired in this experimental model.

The clinical implications of the data obtained from these experiments may be summarized as follows. If the injured brain has an impaired pressure autoregulation and a BBB with an increased permeability to crystalloids then transcapillary fluid exchange will be highly dependent on variations in systemic arterial blood pressure. Under conditions with increased BBB permeability to crystalloids a decrease in tissue pressure will cause a net transport of fluid from the capillaries into the interstitial space and, as discussed above, all surgical treatments of increased ICP are associated with a decrease in tissue pressure. 


\section{The Lund concept}

The "Lund concept" is based on the physiological considerations above and can be summarized in four paragraphs.

\section{Reduction of stress response and cerebral energy metabolism}

Stress response is reduced by liberal use of sedatives (benzodiazepines) and analgesics (opioids). A further reduction of the stress response and catecholamine release is obtained by a continuous infusion of low-dose thiopental $\left(0.5-3 \mathrm{mg} \cdot \mathrm{kg}^{-1} \cdot \mathrm{h}^{-1}\right)$ and fentanyl $\left(2-5 \mu \mathrm{g} \cdot \mathrm{kg}^{-1} \cdot \mathrm{h}^{-1}\right)$ but also by treatment with the $\beta_{1^{-}}$ antagonist metoprolol and the $\alpha_{2}$-agonist clonidine (see below). The dose of thiopental is kept low to avoid cardiac inhibition, pulmonary complications and other side effects (22).

\section{Reduction of capillary hydrostatic pressure}

Mean arterial blood pressure is reduced to the physiological level for the age of the individual patient with a combination of the $\beta_{1}$-antagonist metoprolol $\left(0.2-0.3 \mathrm{mg} \cdot \mathrm{kg}^{-1} \cdot 24 \mathrm{~h}^{-1}\right.$ i.v. $)$ and the $\alpha_{2}$-agonist clonidine (0.4-0.8 $\mu \mathrm{g} \cdot \mathrm{kg}^{-1} \mathrm{x} 4-6$ i.v.) $(2,3,9)$. The antihypertensive treatment is initiated after evacuation of focal mass lesions when the patients are clearly normovolemic as obtained by red cell and albumin/plasma transfusions to normal albumin and haemoglobin values and to a normal central venous pressure. A CPP of 60-70 $\mathrm{mm} \mathrm{Hg}$ is considered optimal but, if necessary to control ICP, a transient decrease in CPP to 50 $\mathrm{mm} \mathrm{Hg}$ for adults and $40 \mathrm{~mm} \mathrm{Hg}$ for children is accepted. Thiopental also has a precapillary vasoconstrictor effect, which will contribute to lowering the intracapillary hydrostatic pressure.

III. Maintenance of colloid osmotic pressure and control of fluid balance

Red cell transfusions and albumin are given to achieve normal values $(\mathrm{Hb} / \mathrm{s} 125-140 \mathrm{~g} / \mathrm{l}, \mathrm{alb} / \mathrm{s} \approx 40 \mathrm{~g} / \mathrm{l})$ to ensure normovolemia and to optimise oxygen supply. The albumin/plasma/blood transfusions also serve the purpose of obtaining a normal colloid osmotic pressure favouring transcapillary absorption. A balanced or moderately negative fluid balance is a part of the treatment protocol and is achieved by diuretics (furosemide) and albumin infusion. All patients are given a low calorie enteral nutrition (max energy supply $\left.15-20 \mathrm{kcal} \cdot \mathrm{kg}^{-1} \cdot 24 \mathrm{~h}^{-1}\right)$.

\section{Reduction of cerebral blood volume}

Intracranial blood volume may be reduced both on the arterial side with thiopental (15) and on the venous side with DHE $(4,9,13,14)$. DHE is only given when other treatments are insufficient and always at the lowest dose necessary to reduce intracranial pressure. Since the therapy above (paragraph I-III) is usually 
successful DHE is rarely used. When given it should not be administered for more than five days in order to minimize the risks of compromising peripheral circulation, in particular in patients with fractures of the extremities or renal insufficiency. The maximum doses of DHE used are: $0.8 \mu \mathrm{g} \cdot \mathrm{kg}^{-1} \cdot \mathrm{h}^{-1}$ day one, 0.6 $\mu \mathrm{g} \cdot \mathrm{kg}^{-1} \cdot \mathrm{h}^{-1}$ day two, $0.4 \mu \mathrm{g} \cdot \mathrm{kg}^{-1} \cdot \mathrm{h}^{-1}$ day three, $0.2 \mu \mathrm{g} \cdot \mathrm{kg}^{-1} \cdot \mathrm{h}^{-1}$ day four, and $0.1 \mu \mathrm{g} \cdot \mathrm{kg}^{-1} \cdot \mathrm{h}^{-1}$ day five.

\section{Cerebral energy metabolism - relation to cerebral perfusion pressure}

A reduction of CPP might jeopardize cerebral energy metabolism in patients with increased ICP especially in vulnerable regions such as the penumbra zones surrounding focal mass lesions (7). The intracerebral microdialysis technique permits bedside analyses of compounds reflecting energy metabolism (glucose, pyruvate, lactate) and indicators of excessive concentration of excitatory

Fig 1 transmitters (glutamate) as well as cell degradation (glycerol) (figure 1). The levels obtained during neuro intensive care can be compared to reference levels obtained in the normal human brain (18) and in patients with manifest cerebral ischemia (24). By inserting multiple intracerebral catheters during open surgery it is possible to choose areas of interest i.e. the zones surrounding an evacuated focal lesion (7).

Fig 2 Figure 2 summarizes resent data, which support the view that in patients treated according to the "Lund concept" the lactate/pyruvate ratio (cytoplasmatic redox state) is usually not affected in the vulnerable penumbra zone until CPP below $50 \mathrm{mmHg}$ (16). Since cerebral biochemistry is monitored and displayed bedside therapeutic interventions are instituted if in an individual patient CPP is considered to be too low.

\section{Clinical results}

Ideally all clinical therapies should be based on randomised controlled studies. However, there are virtually no such studies to support any specific treatment for increased ICP (23). The only randomised clinical trial that has compared the consequences of targeting different levels of CPP failed to show a long-term benefit of increasing CPP above $70 \mathrm{mmHg}$ (19). In a recent review on the management of cerebral perfusion pressure after head trauma it was concluded that it seemed likely that a CPP of 60 $\mathrm{mmHg}$ provided adequate perfusion for most patients with severe traumatic brain injuries (20). Further, pharmacologically induced hypertension was recently shown to cause a further increase in ICP (17). Clinical outcome of volume-targeted therapy according to the "Lund-concept" has been reported from four Swedish neurosurgical centres $(5,6,11,12)$. All four studies have shown a remarkably low mortality. In the original study, which included a selected group of patients with very severe traumatic brain lesion 
and ICP above $25 \mathrm{mmHg}$ in spite of conventional treatment, the decrease in mortality was from $47 \%$ to $8 \%$ (5). The significant decrease in mortality was associated with significant increases in the groups of "good recovery" and "moderate disability" but did not increase the number of patients in the groups of "severe disability" or "vegetative state".

\section{References:}

1. Asgeirsson B, Grände PO (1994) Effects of arterial and venous pressure alterations on transcapillary fluid exchange during raised tissue pressure. Intensive Care Med 20:567-572

2. Asgeirsson B, Grände PO, Nordström CH (1994) A new therapy of post-trauma brain oedema based on haemodynamic principles for brain volume regulation. Intensive Care Med 20:260-267

3. Asgeirsson B, Grände PO, Nordström CH, Berntman L, Messeter K, Ryding E (1995) Effects of hypotensive treatment with $\alpha 2$-agonist and $\beta 1$-antagonist on cerebral hemodynamics in severe head injury. Acta Anasthesiol Scand 39:347-351

4. Asgeirsson B, Grände PO, Nordström CH, Messeter K, Sjöholm A (1995) Cerebral hemodynamic effects of dihydroergotamine in patients with intracranial hypertension after severe head injury. Acta Anaesthesiol Scand 39:922-930

5. Eker C, Asgeirsson B, Grände PO, Schalén W, Nordström C-H (1998) Improved outcome after severe head injury with a new therapy based on principles for brain volume regulation and improved microcirculation. Critical Care Medicine 26:1881-1886

6. Elf K, Nilsson P, Enblad P (2002) Outcome after traumatic brain injury improved by an organized secondary insult program and standardized neurointensive care. Crit Care Med 30:2129-2134

7. Engström M, Polito A, Reinstrup P, Romner B, Ryding E, Ungerstedt U, Nordström CH:

Intracerebral microdialysis in clinical routine - the importance of catheter location. J Neurosurg In press 2005

8. Fenstermacher JD (1984) Volume regulation of the central nervous system. In: Staub NC, Taylor AE (eds) Edema. Raven Press, New York, pp383-404

9. Grände PO, Asgeirsson B, Nordström CH (2002) Volume targeted therapy of increased intracranial pressure: the Lund concept unifies surgical and non-surgical treatments. Acta Anaesthesiol Scand 46: 929-941 
10. Messeter K, Nordström CH, Sundbärg G, Algotsson L, Ryding E (1986) Cerebral hemodynamics in patients with acute severe head trauma. J Neurosurg 64:231-237

11. Naredi S, Edén E, Zäll S, Stephensen H, Rydenhag B (1998) A standardized

neurosurgical/neurointensive therapy directed toward vasogenic edema after severe traumatic brain injury: clinical results. Intensive Care Med 24:446-451

12. Naredi S, Olivecrona M, Lindgren A, Östlund AL, Grände PO, Koskinen LOD (2001) An outcome study of severe traumatic head injury using the "Lund therapy" with low-dose prostacyclin. Acta Anaesthesiol Scand 45:401-405

13. Nilsson F, Messeter K, Grände PO, Rosén I, Ryding E, Nordström CH (1995) Effects of dihydroergotamine on cerebral circulation during experimental intracranial hypertension. Acta Anaesthesiol Scand 39:916-921

14. Nilsson F, Nilsson T, Edvinsson L, Björkman S, Nordström CH (1997) Effects of dihydroergotamine and sumatriptan on isolated human cerebral and peripheral arteries and veins. Acta Anaesthesiol Scand 41:1257-1262

15. Nordström CH, Messeter K, Sundbärg G, Schalén W, Werner M, Ryding E (1988) Cerebral blood flow, vasoreactivity, and oxygen consumption during barbiturate therapy in severe traumatic brain lesions. J Neurosurg 68: 424-431

16. Nordström CH, Reinstrup P, Xu W, Gärdenfors A, Ungerstedt U (2003) Assessment of the lower limit for cerebral perfusion pressure in severe head injuries by bedside monitoring of regional energy metabolism. Anesthesiology 98: 809-814

17. Oertel M, Kelly DF, Lee JH, McArthur DL, Glenn TC, Vespa P, Boscardin WJ, Hovda DA, Martin NA (2002) Efficacy of hyperventilation, blood pressure elevation, and metabolic suppression therapy in controlling intracranial pressure after head injury. J Neurosurg 97:1045-53

18. Reinstrup P, Ståhl N, Hallström Å, Mellergård P, Uski T, Ungerstedt U, Nordström CH (2000) Intracerebral microdialysis in clinical practice. Normal values and variations during anaesthesia and neurosurgical operations. Neurosurgery 47:701-710

19. Robertson CS, Valadka AB, Hannay J, Contant CF, Gopinah SP, Cormio M, Uzura M, Grossman RG (1999) Prevention of secondary ischemic insults after severe head injury. Crit Care Med 27:20862095 
20. Robertson CS (2001) Management of cerebral perfusion pressure after traumatic brain injury. Anesthesiology 95:1513-1517

21. Schalén W, Messeter K, Nordström CH (1991) Cerebral vasoreactivity and the prediction of outcome in severe traumatic brain lesions. Acta Anaesthesiol Scand 35:113-122

22. Schalén W, Messeter K, Nordström CH (1992) Complications and side effects during thiopentone therapy in patients with severe head injuries. Acta Anaesthesiol Scand 36:369-377

23. Slavic RS, Rhoney DH: Pharmacological management of severe traumatic brain injury: an evidence-based review. J Inf Pharmacother 2000, www.informedpharmacotherapy.com

24. Ståhl N, Mellergård P, Hallström Å, Ungerstedt U, Nordström CH (2001) Intracerebral microdialysis and bedside biochemical analysis in patients with fatal traumatic brain lesions. Acta Anaesthesiol Scand 45: 977-985 


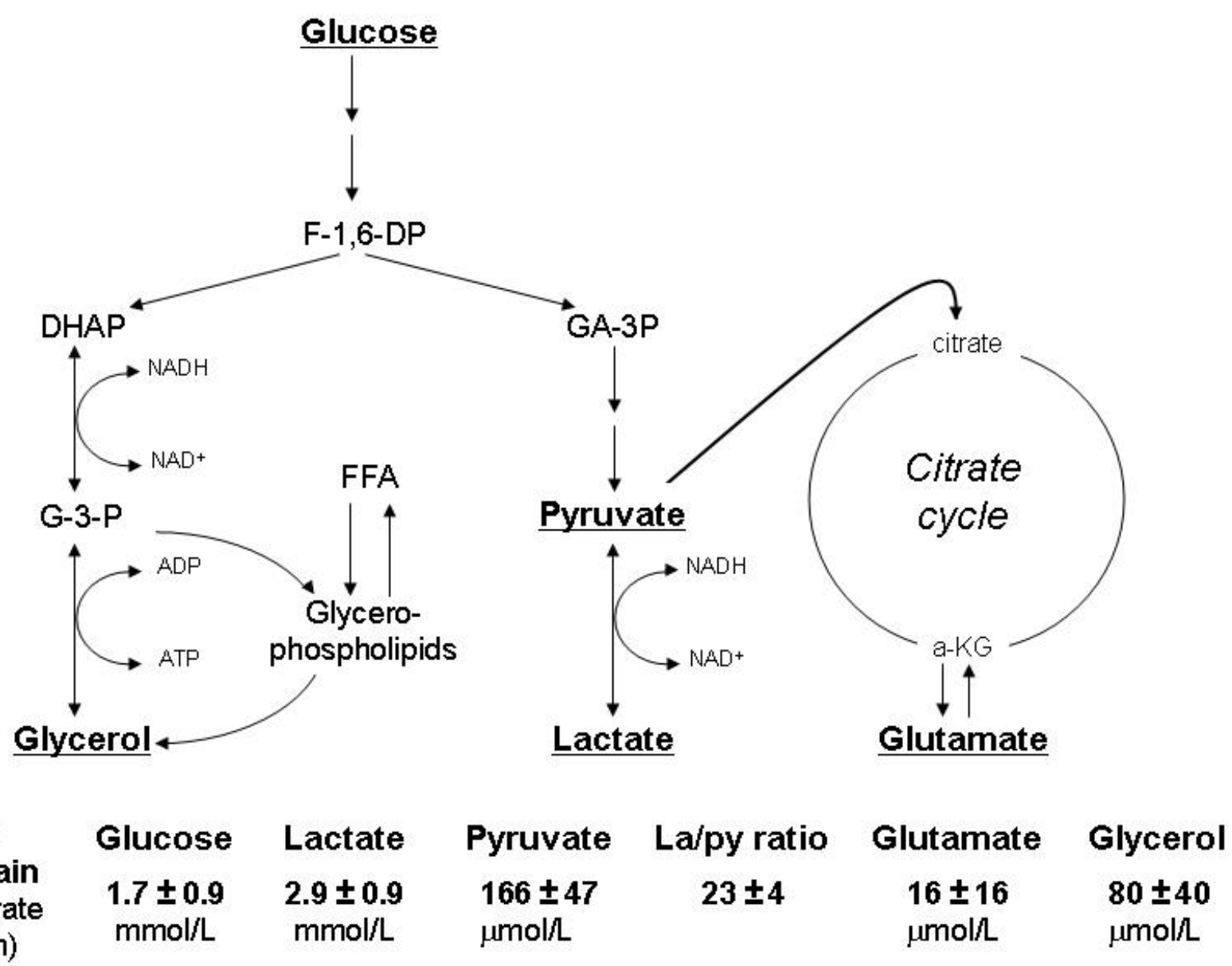

Figure 1. Simplified diagram of intermediary metabolism of the glycolytic chain and its relation to the formation of glycerol and glycerophospholipids and to the citric acid cycle. Abbreviations: Fructose-1,6diposphate (F-1,6-DP); Dihydroxyacetone-phosphate (DHAP); Glyceraldehyde-3-phosphate (GA-3P); Glycerol-3-phosphate (G-3-P); Free fatty acids (FFA); $\alpha$-ketoglutarate ( $\alpha$-KG). Underlined metabolites are measured bedside with enzymatic techniques. References levels of the various metabolites for normal human brain obtained from (18). 


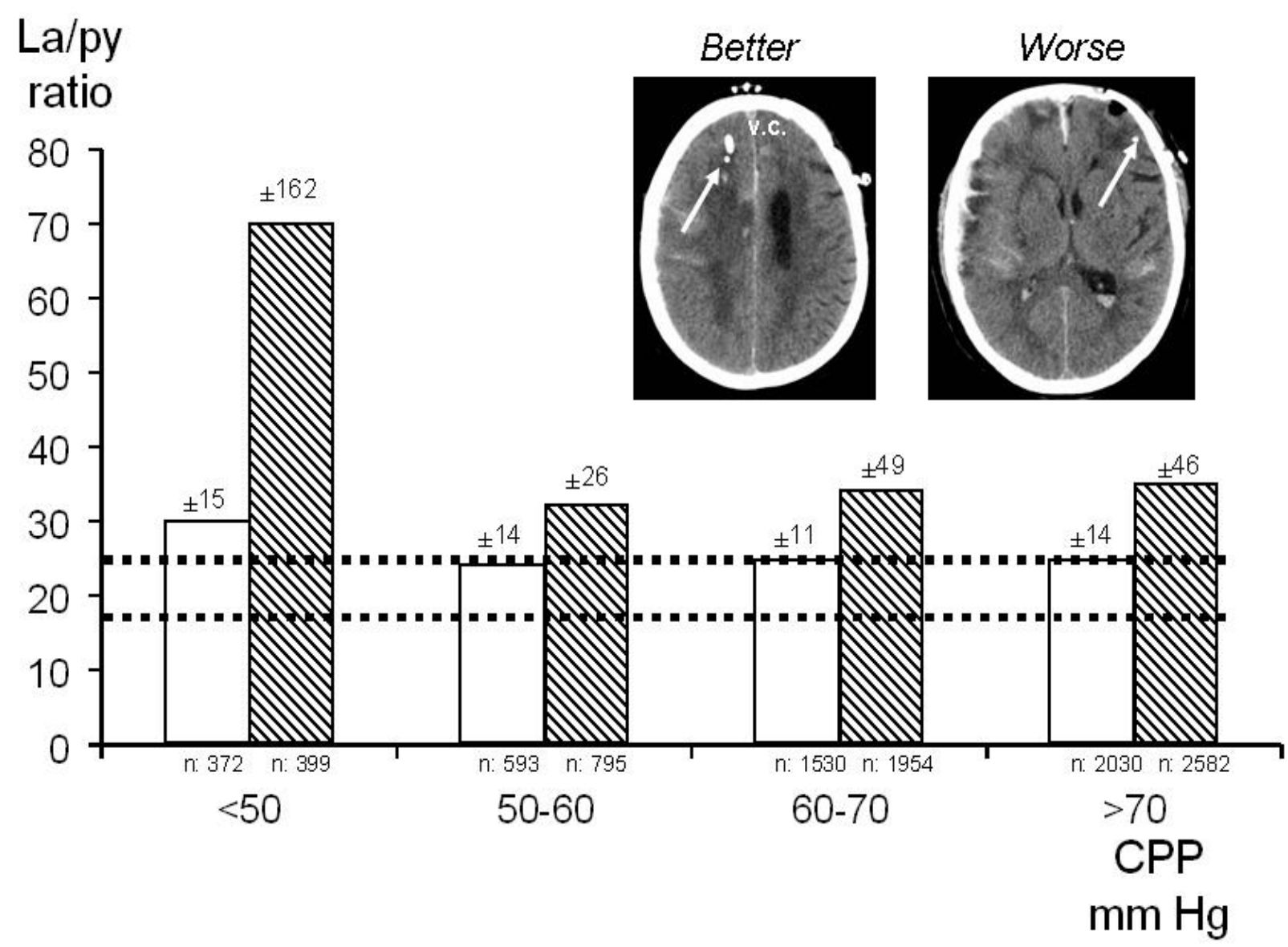

Figure 2. Mean levels \pm S.D. for the lactate/pyruvate (la/py) ratio (n: 7,704 measurements) in the "better" (white) and "worse" (striped) positions in relation to four ranges of CPP. The positioning of the microdialysis catheters in the "worse" (penumbra; surrounding the evacuated haemorrhagic contusion) and the "better" (close to the ventricular catheter - v.c.) areas are shown (arrows). The broken lines indicate the range (mean \pm S.D.; $23 \pm 4$ ) in normal human brain during wakefulness. Data from Nordström et al (16). 